\title{
Study of car emissions in the Athens Restriction Ring from the mid 1980s to 2007 with a prediction scenario for 2011 using air quality indices
}

\author{
A. Loster-Mańka ${ }^{1}$, K. Karkalis ${ }^{2}$, G. Arapis ${ }^{2} \&$ M. Jedziniak ${ }^{1}$ \\ ${ }^{1}$ KOMAG Institute of Mining Technology, Poland \\ ${ }^{2}$ Agricultural University of Athens, Greece
}

\begin{abstract}
The main objective of this paper is the analysis of the change in car emissions from 1986 to 2007 and by consequence, their impact on the general atmospheric conditions in the city of Athens in correlation with the Athens Traffic Restriction Ring.

At the first stage, an observation of the increment of the vehicle fleet in the city of Athens from the mid 1980s to 2007 was made, and its impact on the atmospheric conditions was assessed. At the second stage, based on this data, a possible car fleet number in 2011 was predicted. The different traffic volume data, obtained and elaborated between the period 1986 and 2007, shows no significant increment of the traffic flow inside the Athens Restriction Ring. However, an increment of traffic volume (number of vehicles) was found in the observation points situated outside the Ring. Concentrations of particular pollutants $(\mathrm{CO}, \mathrm{NO}$, $\mathrm{NO}_{2}, \mathrm{SO}_{2}$ and PM10) decreased, despite the fact that the number of vehicles remained constant inside the Ring, due to new technology. The decrease is, most of the time, not sufficient to keep pollution levels in compliance with the EU legislation limits. A prediction for the year 2011 was made on the basis of the trend line obtained while using traffic volume data for the period between 1986 and 2007. For the year 2011, the number of cars inside the Athens Restriction Ring will not change. However, the trend outside the Ring shows the increment in traffic volume in the next two years. As a result of using COPERT IV, a strong correlation between vehicle emissions and pollution concentrations was found at a factor of 0.91 .
\end{abstract}


Keywords: Athens Restriction Ring, air pollution, vehicle emission.

\section{Introduction}

This study results from a cooperation action in the scientific and technical research in the field of transport called "Towards the definition of a measurable environmentally sustainable transport" (COST 356) [1]. Several members, coming from different countries all over Europe, are involved. The Action began on October 14, 2005 and finished in January 2010.

Athens sprawls across the central plain of Attica at the Saronic Gulf and at the Northern part is surrounded by mountains. This specific location causes a problem with the free propagation of pollutants. A breeze coming from the sea during the day pushes the pollutants to the land and the mountains surrounding the city stop the pollutants. Additionally, high temperatures during summertime cause smog.

The Athens Traffic Restriction Ring is a traffic measure that aims to alleviate environmental pollution, and the traffic congestion in the centre of Athens [2]. It means that defined central traffic roads in the city of Athens are restricted to circulation (from 07.00 to 20.00 during working days) by all private vehicles according to their matriculation plate last number. If the driver's plate number of the vehicle ends with an even number, the given vehicle can circulate during the even calendar days of the running month. If the matriculation plate number of the vehicle ends with an odd number, the given vehicle can circulate during the odd calendar days of the running month. In exception are those private cars whose owners live inside the ring, rented cars, private cars used for special

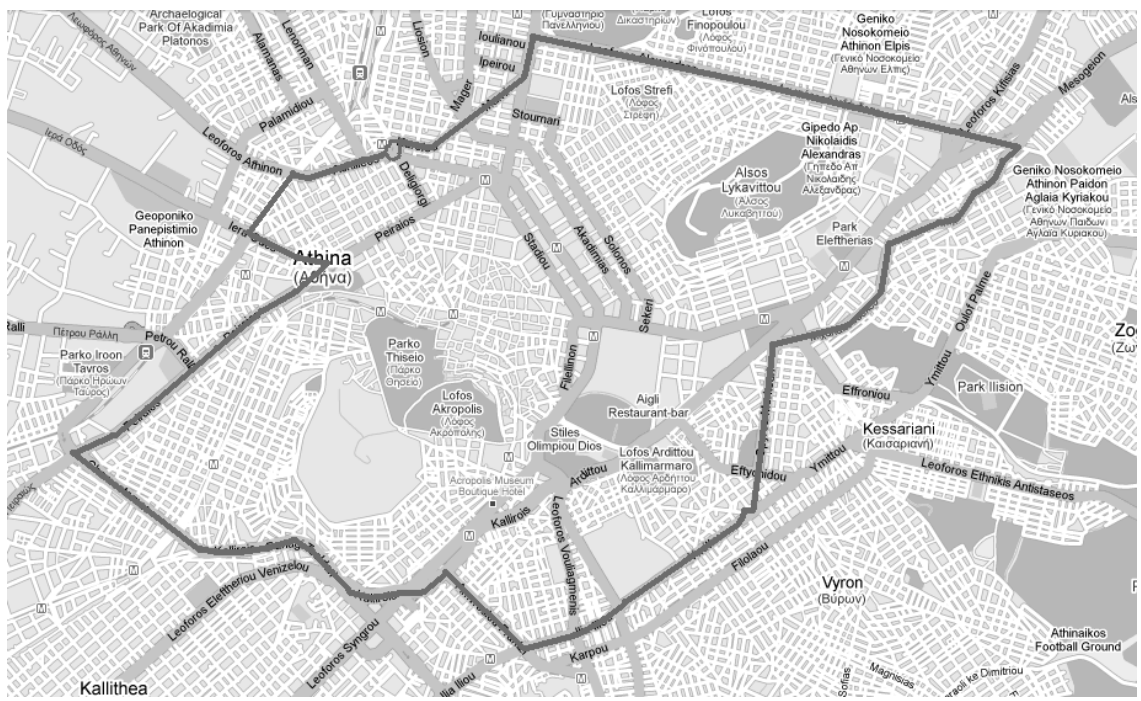

Figure 1: Athens Traffic Restriction Ring - the line shows the boundaries of the Ring. 
public services or emergency (for example doctors trying to reach a patient in case of emergency, or people trying to reach a hospital and so on) and finally all hybrid cars. Taxis and public buses have free access.

The Ring has been used since 1982 as a measure for the control of smog and atmospheric pollution in the Greek capital. Apart from The Athens Traffic Restriction Ring, the use of diesel vehicles has also been restricted since 1982. Only taxis equipped with Diesel engines can move in the restriction ring.

The physical boundaries of the traffic restriction ring coincide with the centre of Athens and are defined by the traffic roots/Avenues covering a surface of approximately $14.25 \mathrm{~km}^{2}$ (see Figure 1).

The functional validity of the Athens Traffic Restriction Ring needs to be verified at present due to the fact that the Restriction Ring was updated in the 80s when there were about 400,000 cars in Athens [2]. This number has increased many times within last 20 years, changing the whole traffic structure of Athens.

Even if the traffic in the city centre is somehow alleviated, the traffic in avenues that define the boundaries of The Ring increases due to over congestion. Since emissions are not stationary but flow all over the city, one could assume that the Restriction Ring increases smog instead of preventing it.

\section{Methodology}

Information data as regards pollutants concentration and traffic intensity, used in the analysis, is collected from the measuring stations located inside Athens Restriction Ring, in its vicinity $(1 \mathrm{~km})$ and outside its border. It was assumed that such a selection of monitoring stations would enable determining the impact of Athens Traffic Restriction Ring on quality of local air. The measuring points were selected in such a way to have an access to information about traffic intensity near the measuring point at the same time. The monitoring station, for

Table 1: The location of stations in the monitoring network in Athens [5].

\begin{tabular}{|c|c|c|c|c|c|c|}
\hline \multirow{2}{*}{ Station location } & \multicolumn{5}{|c|}{ Pollutants measured } & \multirow{2}{*}{ Meteo } \\
\cline { 2 - 6 } & $\mathrm{SO}_{2}$ & $\mathrm{NO}_{\mathrm{x}}$ & $\mathrm{CO}$ & $\mathrm{O}_{3}$ & $\mathrm{PM} 10$ & \\
\hline Athinas $^{1)}$ (ATH) & $\mathrm{x}$ & $\mathrm{x}$ & $\mathrm{x}$ & $\mathrm{x}$ & & \\
\hline Aristotelous $^{1)}(\mathrm{ARI})$ & $\mathrm{x}$ & $\mathrm{x}$ & & & $\mathrm{x}$ & \\
\hline Patision $^{2)}(\mathrm{PAT})$ & $\mathrm{x}$ & $\mathrm{x}$ & $\mathrm{x}$ & $\mathrm{x}$ & & $\mathrm{x}$ \\
\hline Goudi $^{2)}(\mathrm{GOU})$ & & $\mathrm{x}$ & & & $\mathrm{x}$ & \\
\hline Marousi $^{3)}$ (MAR) & $\mathrm{x}$ & $\mathrm{x}$ & $\mathrm{x}$ & $\mathrm{x}$ & $\mathrm{x}$ & $\mathrm{x}$ \\
\hline
\end{tabular}

1) The stations inside the Athens Restriction Ring; ${ }^{2)}$ the stations situated on the "border" of the Ring ( $1 \mathrm{~km}$ max distance); ${ }^{3)}$ the stations outside the Ring (over $1 \mathrm{~km}$ ). 
which comparison analysis (correlation between vehicle emission and pollution concentration) was made, was the station that provided most detailed information.

Data of concentration of pollutants [3, 4] due to the traffic in the Athens region have been collected and analyzed over the period from 1986 up to 2007 for the following 5 districts (see Table 1) in order to study the traffic volume possible impact on air pollution. The regions were: Athinas, Aristotelus, Patision, Goudi and Marousi.

In the same manner, the data of traffic volumes from different avenues near the aforementioned pollution monitoring stations were collected in order to study changes and estimate future trends in traffic volume. The avenues where: Athinas, Aristotelous, $3^{\text {rd }}$ Septemvriou Alexandras, Patision, Ilision, Kimis, Louis Olimpionikou Spirou. A statistical analysis was carried out in order to evaluate changes in traffic flow between 1986 and 2007 and to make prediction of possible traffic changes in the next two years (2009-2011).

In order to estimate the vehicle emissions inside the Athens Restriction Ring the software COPERT IV was used [6, 7]. The model, developed within the framework of the activities of the European Topic Centre on Air Emissions, can be used by EEA member countries for the compilation of CORINAIR emission inventories.

\section{Description of the main results obtained}

After having compared different collected data, it becomes evident that despite of an increase in the vehicle fleet from 400,000 vehicles to over 3,400,000 [8] in

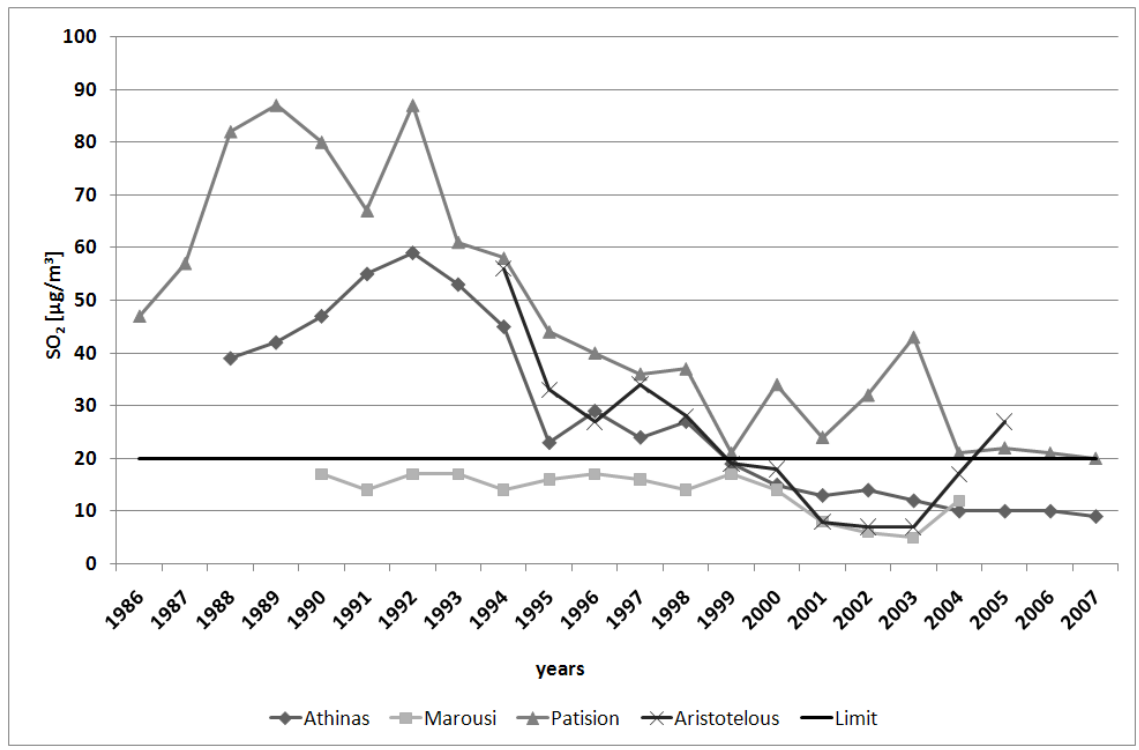

Figure 2: Levels of $\mathrm{SO}_{2} \mu \mathrm{g} / \mathrm{m}^{3}$ in the monitoring stations of Athinas, Marousi, Patision and Aristotelus. 


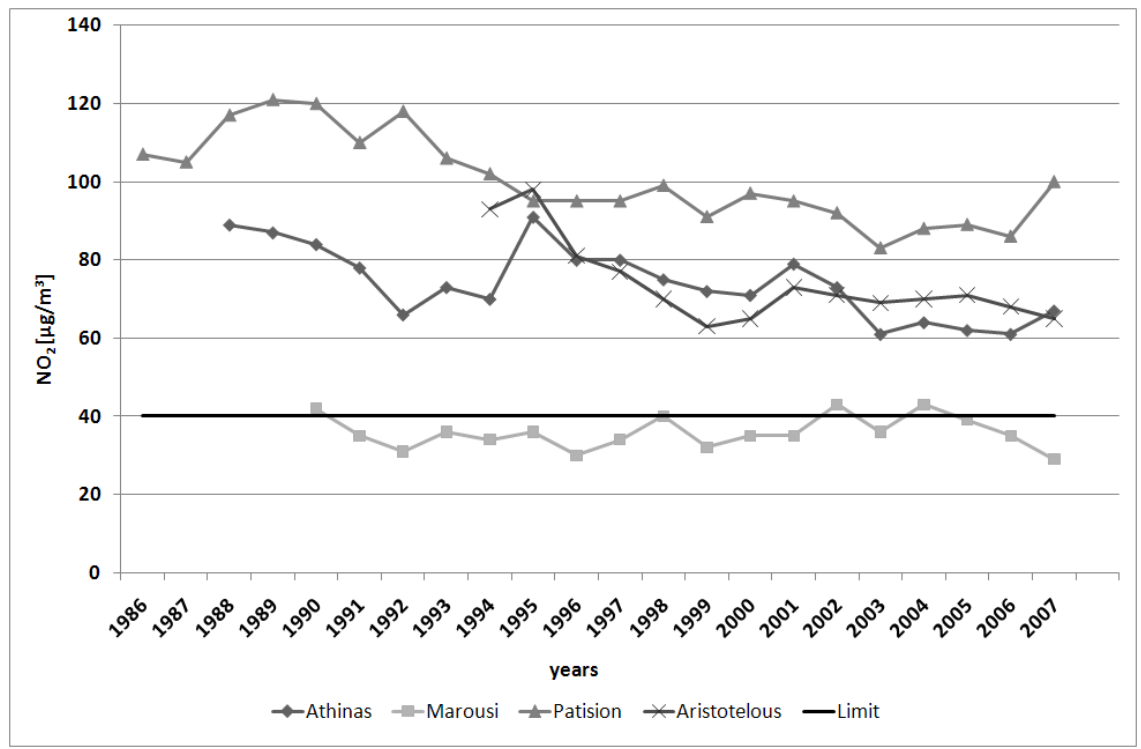

Figure 3: Levels of $\mathrm{NO}_{2} \mu \mathrm{g} / \mathrm{m}^{3}$ in the monitoring stations of Athinas, Marousi, Patision and Aristotelus.

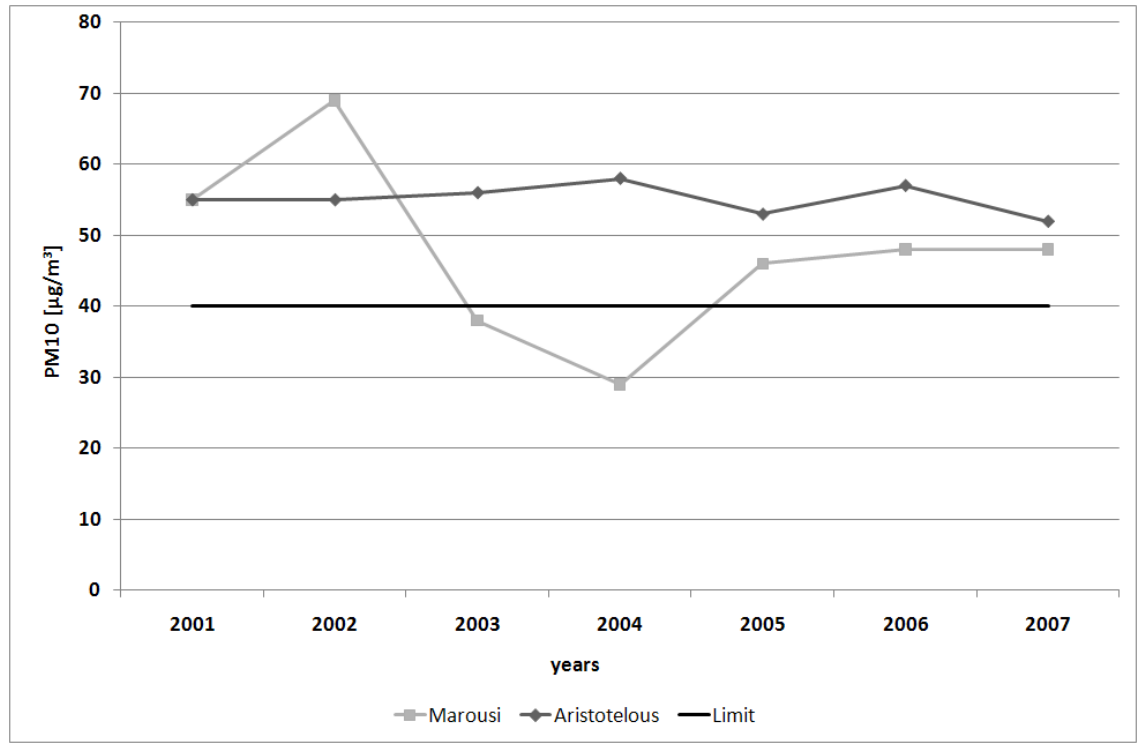

Figure 4: Levels of PM10 $\mu \mathrm{g} / \mathrm{m}^{3}$ in the monitoring stations of Marousi and Aristotelous. 
the Greater Athens region these past decades (1980-2007), the traffic volumes inside the ring remain relatively constant. On the other hand, levels of pollutants, as monitored by the five urban traffic stations inside the Athens Restriction Ring, are most of the time above the limits of the EU [9] despite an upgrade in car fleet technology due to the European emission standards [10]. To compare, the average annual pollutants concentrations were used.

The data collected for those regions inside the Athens Restriction Ring (e.g. Athinas - see Figure 5) indicate that the level of concentration of pollutants (for example $\mathrm{NO}_{2}$ ) has recorded values above the EU limits for all the years from 1986 to 2007. Traffic flow is maintained constant. The same applies to those regions situated in the distance less than one kilometre from the Athens Restriction Ring borders like Patision Avenue (Figure 6). On the other hand we can see that for areas that are in a relevant distance outside the Traffic Restriction Ring (over $1 \mathrm{~km}$ ) like Marousi (Figure 7) the concentration levels (for example $\mathrm{NO}_{2}$ ) are quite stable, below the EU limits while the traffic volume of vehicles seems to be increasing in number from 1986 to 2007.

In general, all the different traffic volume data obtained and elaborated over the period 1986 and 2007 show no significant increment of the traffic flow inside and on the borders of the Athens Restriction Ring. However, an increment of traffic volume (number of vehicles) has been found in the observation points situated outside the Ring. This is probably due to the fact that from the mid-eighties there has been an increase in the number of cars market sales in Greece and therefore in the Great Athens area. However, the traffic volumes inside the ring remain more or less constant for the same period. The engines of

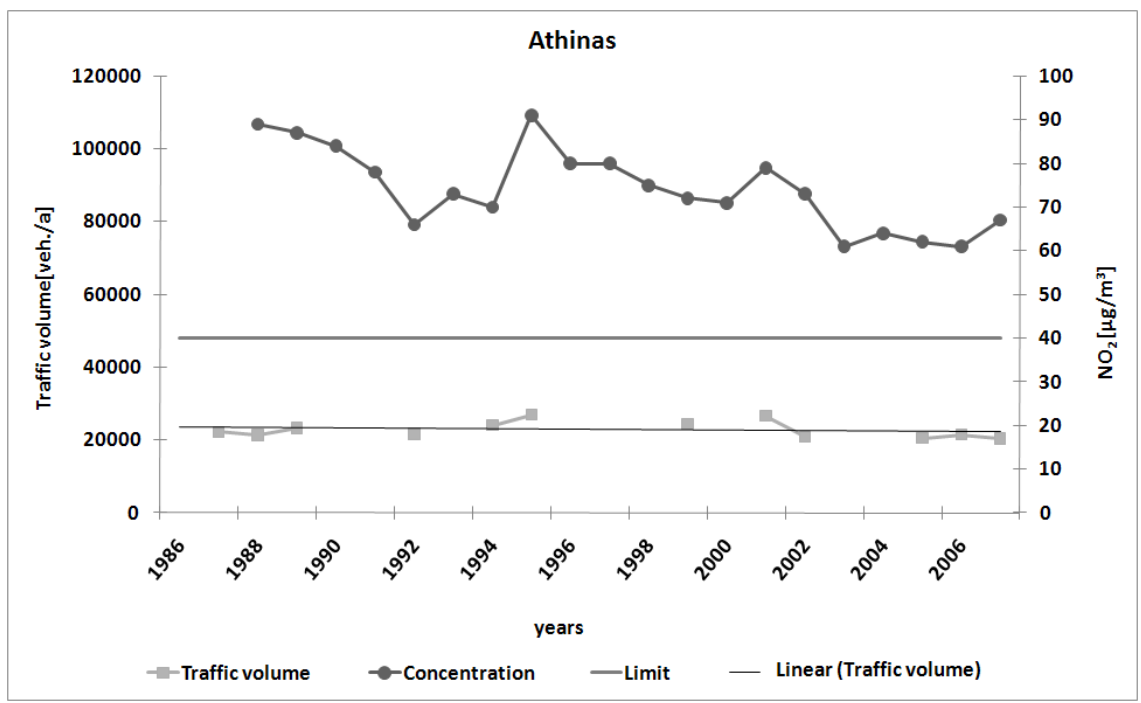

Figure 5: Levels of $\mathrm{NO}_{2} \mu \mathrm{g} / \mathrm{m}^{3}$ and traffic volume per year observed in the monitoring station point in Athinas Avenue. 


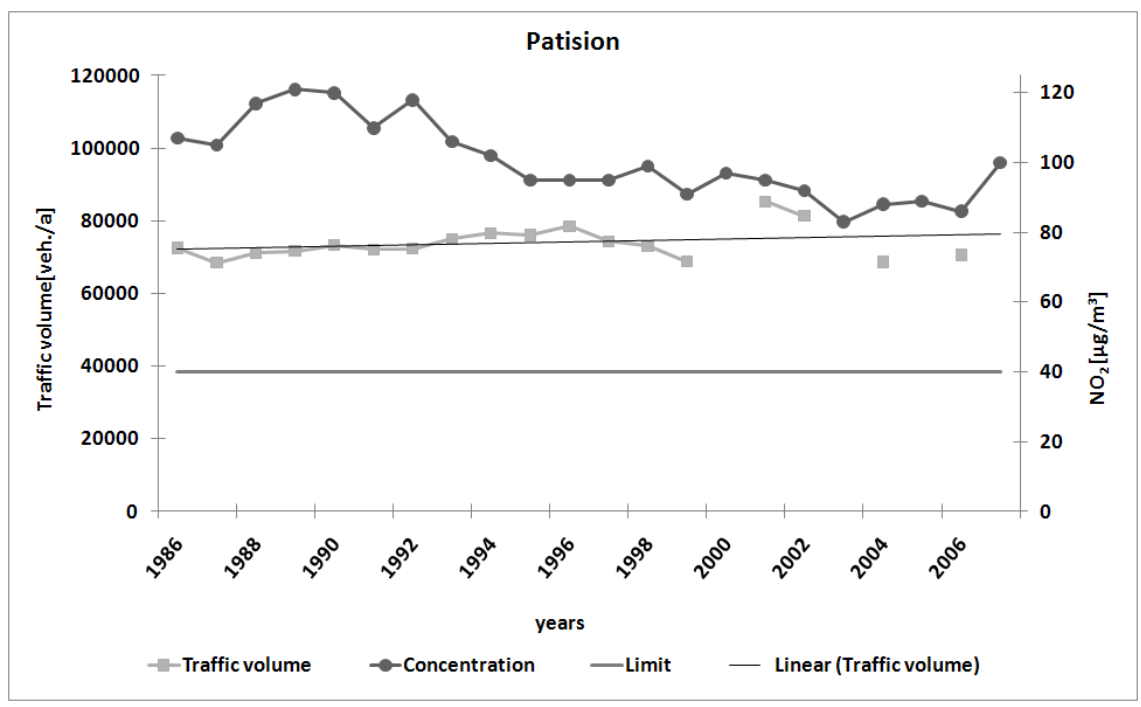

Figure 6: Levels of $\mathrm{NO}_{2} \mu \mathrm{g} / \mathrm{m}^{3}$ and traffic volume per year observed in the monitoring station point of Patision.

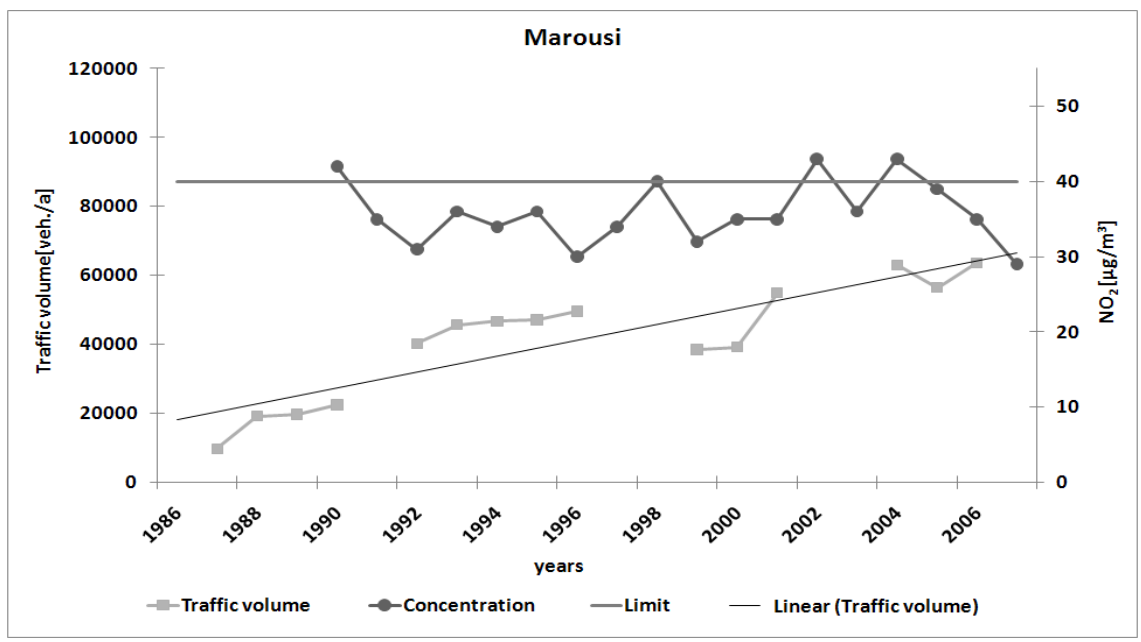

Figure 7: Levels of $\mathrm{NO}_{2} \mu \mathrm{g} / \mathrm{m}^{3}$ and traffic volume per year observed in the monitoring station point of Marousi.

the vehicles had been improved in the 1980s up to 2007, with reference to the European emission standards. This trend can be observed on the basis of the data from traffic pollution monitoring stations situated inside the Athens Restriction Ring. Concentrations of particular pollutants (CO, NO, $\mathrm{NO}_{2}, \mathrm{SO}_{2}$ and PM10) have decreased despite of the fact that the number of vehicles has remained constant inside the Ring. 
This decrease is most of the time not sufficient in order to keep the pollution levels in compliance with the EU legislation limits [9]. In order to alleviate the atmospheric conditions in Athens a "Green" enhancement of the vehicles engine technology alone could prove to be insufficient in the long term if not supported by other solutions (for example: an expansion of the Metro lines, pedestrian zones, a further development of the sustainable public transport, bicycle paths, parks).

A prediction for the year 2011 has been made on the basis of trend line obtained while using traffic volume data for the period over 1986 and 2007 (see Figure 5). For the year 2011, the number of cars inside the Athens Restriction Ring will not change. However, the trend remaining outside the ring shows the increment in traffic volume in the next 2 years (for Kimis and Olimpionikou an increase of approximately $18 \%$ and $10 \%$ ).

The calculation of vehicle emission has been made for a rough assessment of the Athens Traffic Restriction Ring's ability to mitigate the concentration of pollutants inside the Ring. The obtained results show a correlation between vehicle emission and pollution concentration (see Figure 9). The comparison was made for data (traffic intensity, average annual $\mathrm{NO}_{2}$ concentration) from the same station.

After processing the data using COPERT IV, it becomes obvious that there is a strong correlation between vehicle emission and pollution concentration, the correlation factor is 0.91 .

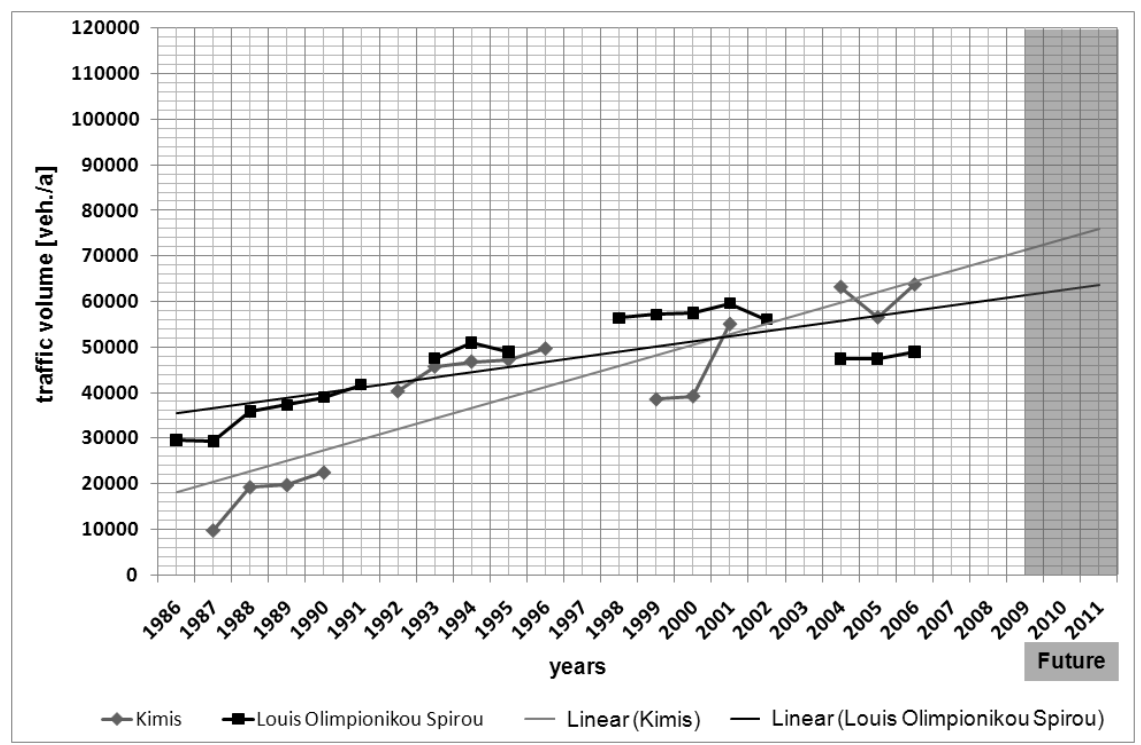

Figure 8: Estimation of future traffic volume on the basis of given data. 


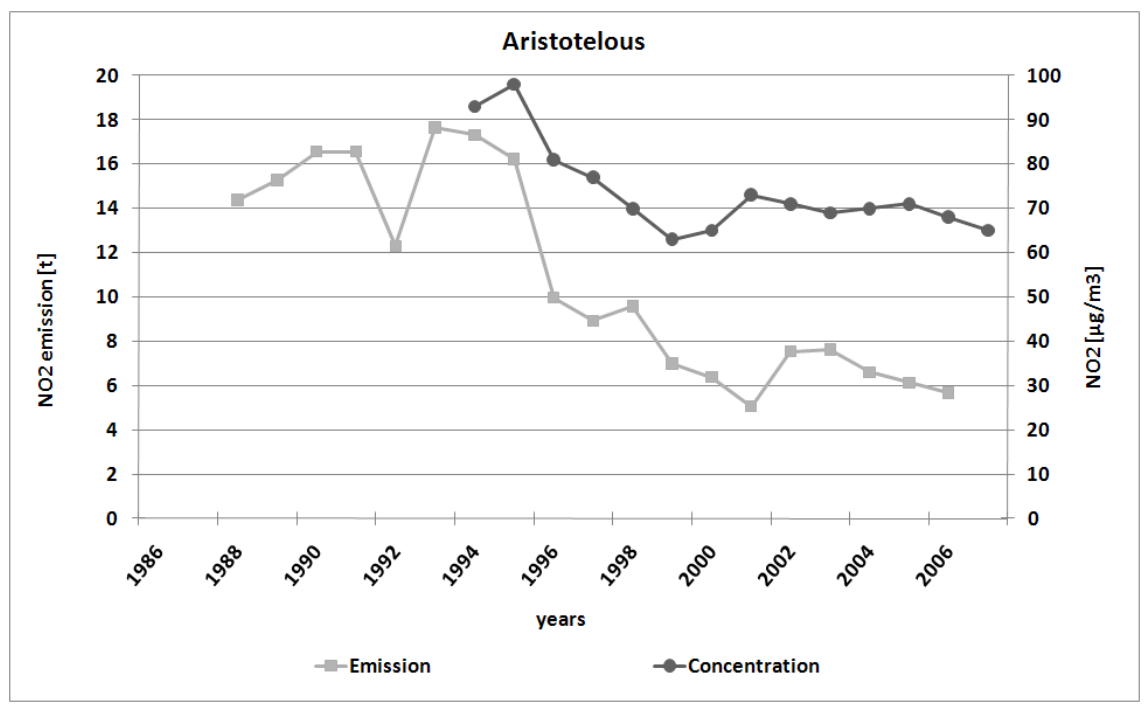

Figure 9: Correlation between vehicle emission and pollution concentration for Aristotelous.

Proposal:

Instead of using an alternation of odd-even numbers in the Athens Restriction Ring, the European emission standards could be used in order to control the frequency of private car vehicle access to the city centre as defined by the Restriction Ring.

\section{Conclusions}

- Decrease of concentration of pollutants inside the Athens Restriction Ring has been found, despite the fact that the number of vehicles has remained constant. On the other hand, for those regions significantly distant from the ring borders $(10 \mathrm{~km})$, the traffic volume increases while the concentration of pollutants is relatively stable.

- Inside the Athens Restriction Ring recorded concentrations of pollutants were over the EU limits for all years from 1986 to 2007. For the areas that are in a relevant distance from the traffic restriction ring (over 10 $\mathrm{km}$ ) the concentration levels of for example $\mathrm{NO}_{2}$ are quite stable under the EU limits.

- An increment of traffic volume in the year 2011 has been estimated. The number of cars inside the Athens Restriction Ring will not change. However, the trend remaining outside the Ring shows an increase of approximately $18 \%$ and $10 \%$.

- On the basis of statistical data and COPERT IV software, the vehicle emission inside the Athens Restriction Ring has been calculated. A strong correlation between vehicle emission and pollution concentration has been found. The correlation factor presented value of 0.91 . 


\section{References}

[1] Loster-Manka A., Karkalis K. \& Arapis G., An example of impact assessment: Athens restriction ring. Indicators of environmental sustainability in transport: An interdisciplinary approach to methods,COST356 Final Report, pp. 307-311, not published yet

[2] Athens Restriction Ring, Wikipedia, the free encyclopedia

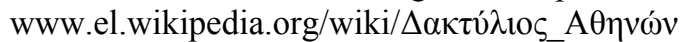

[3] Ministry of Environment, Physical Planning and Public Works

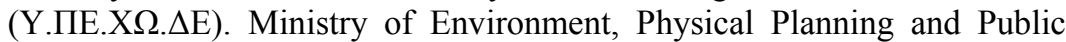
Works Web Site, Athens. www.minenv.gr/4/41/000/2 008i.atmosferiki.ripansi.stin.athina.ekthesi.2007.doc

[4] Hellas in numbers. General Sectretariat Of National Statistical Service Of Greece. www.statistics.gr/eng_tables/hellas_in_numbers_EN.pdf

[5] Air4EU city assessment for Athens; Air4EU. http://www.air4eu.nl/Word/CA_Athens.doc

[6] Generalna Dyrekcja Dróg Krajowych i Autostrad (GDDKiA). Portal Ochrony Srodowiska Web Site, www.oos.pl/pliki/File/copert2/ ZalacznikNr4-v2.pdf

[7] EMEP/CORINAIR Emission Inventory Guidebook - 2007; European Environment Agency (EEA). www.eea.europa.eu/publications/ EMEPCORINAIR5/B710vs6.0.pdf

[8] National Statistical Service of Greece, Statistical Year Book of Greece, The Statistical Information and Publications Division: Pireas, Vol. 1984-2007

[9] Directive 2008/50/EC of the European Parliament and of the Council on ambient air quality and cleaner air for Europe; EUR-Lex, Official Journal of the European Union. www.eur-lex.europa.eu/LexUriServ/LexUriServ. do?uri=OJ:L:2008:152:0001:0044:EN:PDF

[10] European emission standards. Wikipedia, the free encyclopedia. www.en.wikipedia.org/wiki/Euro_III 